\title{
Enfoque actual de la motivación de las sentencias. Su análisis como componente del debido proceso
}

Current approach to motivation in court judgments. Its analysis as an element of due process

\author{
Gastón Fernando Valenzuela Pirotto ${ }^{1}$ \\ ${ }^{1}$ Universidad Católica del Uruguay \\ ORCID: 0000-0003-3720-806X \\ Correo: gastonvp@gmail.com \\ Recibido: $12 / 03 / 2020$ \\ Aceptado: 18/04/2020
}

\section{Resumen:}

El presente artículo versa sobre la investigación científica del fenómeno de la motivación de las sentencias, partiendo desde su origen y evolución hasta su consagración como componente inherente al debido proceso. Asimismo, se expondrán las características que en la actualidad debe revestir toda motivación, su estrecha vinculación con la valoración de la prueba y las consecuencias que provoca su ausencia. A tal fin, se analizará el articulado contenido en el Código General del Proceso uruguayo y los aportes vertidos tanto por la jurisprudencia como por la doctrina nacional y extranjera.

Palabras clave: motivación; sentencia; debido proceso; magistrado; garantías.

\begin{abstract}
:
This article focuses on the scientific research of the phenomenon of the motivation of the conclusions of law in court judgments, starting from its origin and evolution until being established as an inherent element of due process. The features that every motivation must contain at present, as well as its close connection with the evaluation of the evidence, and the consequences its absence entails, will also be described. The sections of the General Code of Procedure of Uruguay and the contributions from jurisprudence and national and foreign doctrine will be analyzed for such purpose.
\end{abstract}

Keywords: motivation; judgment; due process; magistrate; guarantee. 


\section{Introducción}

El presente trabajo tiene por objetivo realizar un estudio sobre la motivación de las sentencias judiciales, desde su origen y evolución hasta su consagración como componente del debido proceso y, por lo tanto, como una garantía constitucional que ha provocado la extensión de sus funciones y su vinculación con el concepto de justificación del ejercicio del poder estatal, no solo frente a las partes del proceso sino además frente a la sociedad en general. Precisamente por ello, por su elevación como garantía inherente al debido proceso, la motivación debe reunir ciertas características entre las que se destacan las vinculadas a la prueba. Finalmente, y a la luz de lo indicado, será analizada la regulación contenida en nuestro Código General del Proceso y las consecuencias que provoca su ausencia.

La motivación de las sentencias puede conceptualizarse como la exposición realizada por el tribunal de las razones que sustentan su decisión, destinada a justificar ante las partes y la sociedad en general cuál ha sido el razonamiento seguido para arribar a determinada solución.

Ya Couture (2007, p. 234) señalaba que la motivación constituía un deber administrativo impuesto al magistrado como manera de fiscalizar su actividad intelectual frente al caso, a efectos de poder comprobar que su decisión es un acto reflexivo, emanado de un estudio de las circunstancias particulares, y no de un acto discrecional de su voluntad autoritaria.

En la actualidad podría señalarse que la motivación de las sentencias se ha erigido en una verdadera garantía inherente al debido proceso que despliega efectos incluso fuera del proceso, constituyéndose de esta manera en su contenido más importante y superando la tradicional posición que la identificaba como un mero requisito formal de las sentencias, entendiéndoselo como un concepto comprensivo tanto de la fundamentación fáctica como de la fundamentación jurídica de aquellas (Vescovi et al., 2000, p. 62; Tarigo, 2004, p. 199). Ahora bien, no siempre fue así e incluso la propia concepción de la motivación como un requisito formal de toda sentencia es una construcción relativamente moderna por lo que la evolución de este concepto merece ser objeto de análisis, tal como se verá a continuación. 


\section{Evolución de la exigencia: De la inexistencia de motivación a su función endoprocesal}

En el derecho romano la motivación de las sentencias no era obligatoria (Calamandrei, 1945, p. 80), no se exigía tal requisito dado que la justicia era obra de los pontífices, patricios y abvocatus, quienes conocían los textos legales y ejercían la iurisdictio (Gozaíni, 2014, p. 703). Esto es, la actividad de juzgar era una tarea reservada a la nobleza por lo que el fundamento y respaldo de sus decisiones se encontraba en su prestigio social (Gil Cremades, 1980, p. 416). Con el derecho justiniano el panorama poco cambió en tanto su recepción se realizó a través de la técnica de la glosa en la que los glosadores acudían a brocardos latinos para justificar las decisiones (Colomer Hernández, 2003, p. 126; Barbieri, 2010, p. 787).

Sin embargo, con las Leyes de Partidas de Alfonso X, en particular la III (Título XVIII y XXI) se estableció el deber de indicar la causa de la orientación en uno u otro sentido (deuen dezir los juezes que juzgaren la alcada porque fallamos en tal razón); solución que, como sostiene Gozaíni (2014, p. 703-704), se reproducirá en varios textos españoles posteriores. Lamentablemente durante el absolutismo español de Carlos III (1759-1788) se prohibió, por medio de la Real Cédula del 23 de junio de 1778, que las sentencias dictadas por las Audiencias fueran motivadas a fin de evitar "cavilaciones de los litigantes" (Peyrano citado por Soba y Gaiero, 2010, p.850).

Como recuerda Abal Oliú (2016, p. 107), el origen moderno del deber de motivación surge tras la Revolución Francesa como una reacción ante la desconfianza de los jueces del Antiguo Régimen que no fundaban sus fallos (mientras que en los sistemas del common law la práctica de argumentar las decisiones judiciales es una institución que se remonta al siglo XII (Atienza citado por Soba y Gaiero, 2010, p. 846). Es que "en la Europa de los siglos XVIII y XIX el rol de tirano era desempeñado por el rey secundado por los jueces por él designados, mientras que el rol del libertador lo asumió, normalmente, el Parlamento" (Risso Ferrand, 2011, p. 147). El temor de que estos jueces se apartaran de lo que dictaran las leyes revolucionarias fue en definitiva lo que llevó (por medio de la ley del 16 de agosto de 1790 y luego reafirmado por el art. 208 de la Constitución del año III) a obligarlos a motivar sus fallos, indicando en qué disposiciones se fundaban. Es por ello que Taruffo (2006, p. 305) indica que la matriz de la que surge 
la afirmación generalizada de la obligatoriedad de la motivación es ideológica y política, más que jurídica o filosófica.

Contemporáneamente en Prusia se desarrolló la idea de la obligación de la motivación de las sentencias, aunque con un fundamento completamente diverso al revolucionario francés. Aquí se conocía el instituto de la "motivación secreta" como una práctica destinada a ser utilizada exclusivamente por el juez de la impugnación. La innovación consistió en la introducción y posterior reglamentación mediante la Ley de reforma general del proceso en 1793 de la obligación de poner por escrito la motivación destinada al conocimiento de las partes de forma de agilizar el trámite en segunda instancia, evitando impugnaciones motivadas en la falta de claridad de la decisión (Taruffo, 2006, p. 305-307).

Por su parte en Chile durante el año 1836 se remitió al Congreso un proyecto de ley que buscaba obtener la fundamentación de los fallos. Este proyecto tuvo el respaldo de Andrés Bello (citado por Gozaíni, 2014, p. 708) que, posiblemente influenciado por las ideas revolucionarias francesas, desde una editorial del periódico El Araucano publicada el 25 de noviembre de 1836, señalaba:

\begin{abstract}
El proyecto de ley propuesto al Congreso en el mensaje que insertamos en el presente número presenta a los chilenos una de las garantías más reales que la legislación pueda ofrecer a un pueblo. Hasta hoy han estado sometidos nuestros derechos a las decisiones arbitrarias de los jueces, que sujetos a las pasiones, errores y preocupaciones que forman el patrimonio de la especie humana, han gozado del ominoso y extravagante privilegio de fallar sobre las cuestiones más importantes sin dar cuenta a la nación de los fundamentos de sus juicios, ni explicaciones satisfactorias de sus operaciones administrativas... Admitir sentencias no fundadas equivale en nuestro concepto a privar a los litigantes de la más precisa garantía que pueden tener para sujetarse a las decisiones judiciales.
\end{abstract}

Es así como se desarrolla el concepto de motivación de las resoluciones como una exigencia dirigida a las partes del proceso (aunque en la Francia revolucionaria también puede advertirse la presencia de la idea de contralor de la actividad judicial, vinculada a la función que será analizada en el próximo capítulo) a efectos de que estén en condiciones de aceptar la decisión de acuerdo a los fundamentos expuestos o de fundar una adecuada impugnación (Landoni et al., 2004, p. 621). 
Sobre la posibilidad de aceptar la decisión, se ha sostenido - con acierto - que una debida motivación facilita el cumplimiento voluntario de las partes, ya que le da mayor credibilidad al proceso de formación de la convicción y decisión (Soba y Gaiero, 2010, p. 852). En cambio, en lo que respecta a la impugnación de la sentencia, como indica Calamandrei (1960), se pone a las partes la posibilidad de "verificar si en el razonamiento que ha conducido al juez a decidir en determinado sentido pueden descubrirse alguno de aquellos defectos que dan motivo a los diversos medios de impugnación" (p. 117). Por su parte, Tarigo (1987) agrega que la motivación constituye una base imprescindible para la eventual impugnación del perdidoso, ya que llega a ser el espejo revelador de los errores del sentenciante (p. 314). Es que la función de control tiene por finalidad el examen crítico de las demás funciones (Barrios de Ángelis, 2005, p. 199), lo que únicamente puede ser realizado en lo que respecta a la función de satisfacción, si existe una adecuada motivación de la resolución.

Por su parte, en el ámbito del Tribunal de lo Contencioso Administrativo, se ha señalado que la motivación de la sentencia que anula un acto adquiere una función especialmente relevante para que la Administración demandada cumpla correctamente el fallo anulatorio. Ello por cuanto debe recomponer la situación de modo de sustituir el acto anulado, lo que requiere una motivación clara, precisa y completa para orientar a la administración en ese aspecto (Castro, 2016).

No solo a las partes estaba (y está) dirigida la motivación, sino también al tribunal ad quem a fin de otorgarle el material necesario para realizar el control y análisis de la sentencia, una vez interpuestos los recursos pertinentes (Landoni et al., 2004, p. 621). E, incluso, la motivación cumple en esta etapa una función de generar autocontrol en el propio tribunal que dicta la sentencia, obligando al magistrado a controlar el sentido y alcance de su decisión y la forma en que la justifica (Santana, 2016, p. 24).

Como se aprecia, se trata de una exigencia vinculada principalmente a las partes como al tribunal que dicta la sentencia y el de alzada, por ello se la ha llamado una función endoprocesal de la motivación. Ahora bien, con el desarrollo del Estado Constitucional de Derecho a esta función se le agregó otra que no la sustituye, sino que la complementa denominada extraprocesal, que será analizada a continuación. 


\section{La constitucionalización del deber de motivación y función extraprocesal}

Si en la actualidad partimos de la base que el deber de motivación deriva del derecho al debido proceso (Gozaíni, 2014, p. 709) y este se erige como un derecho procesal fundamental (Guerra y Guerra, 2018, p. 1093), no cabe más que concluir en su rango constitucional siendo ésta una verificación práctica de la constitucionalización de las garantías judiciales. Es que, como ya señalara Couture (1948), "el Código de Procedimiento Civil [en términos trasladables al CGP] y sus leyes complementarias son el texto que reglamenta la garantía de justicia contenida en la Constitución" (p. 19).

En ese sentido, la Corte Interamericana de Derechos Humanos ha sostenido que el deber de motivación es una de las "debidas garantías" incluidas en el artículo 8.1 de la Convención Americana sobre Derechos Humanos para salvaguardar el derecho a un debido proceso, señalando además que:

El deber de motivar las resoluciones es una garantía vinculada con la correcta administración de justicia, que protege el derecho de los ciudadanos a ser juzgados por las razones que el Derecho suministra, y otorga credibilidad de las decisiones jurídicas en el marco de una sociedad democrática ("caso Apitz Barbera y otros vs. Venezuela", 5/08/2008, Medina, García, Ventura, Franco, May Macaulay, Abreu, párr. 78).

Este fenómeno de constitucionalización de derechos procesales que tuvo su punto de inflexión con el desarrollo del Estado constitucional de Derecho luego de la segunda guerra mundial, puede ser dividido desde un punto de vista teórico en dos grupos en lo que refiere al deber de motivación que deben revestir las resoluciones judiciales.

En un primer grupo se encuentran aquellos ordenamientos jurídicos caracterizados por la irrupción del deber de motivación como componente esencial del debido proceso $\mathrm{y}$, por lo tanto, su reconocimiento como garantía constitucional a través de las disposiciones que refieren a aquel o a las garantías propias que derivan de la forma republicana de gobierno. No obstante, en este grupo los ordenamientos carecen de una previsión expresa referida al deber de motivación de los órganos judiciales. Es el caso de Argentina, Bolivia, Brasil, Chile, Colombia, Costa Rica, El Salvador, Guatemala, 
Honduras, México, Nicaragua, Panamá, Paraguay, Venezuela, y nuestro país (Verbic, 2014).

Luego, un segundo grupo de ordenamientos jurídicos en donde comenzaron a reformarse sus cartas constitucionales que fueron adaptando sus principios, declaraciones y garantías, al compás de la evolución y consagración de los derechos humanos (Gozaíni, 2014, p. 709). Aquí, la garantía de motivación es reconocida expresamente en los textos constitucionales, como lo son los casos de República Dominicana - aunque parecería contemplarla solo en materia penal-, Ecuador, Perú (Verbic, 2014), siendo las constituciones italiana y española los puntos de partida de este grupo. La Constitución ecuatoriana es sumamente detallada en este aspecto incluyendo a la motivación como una garantía que debe contener toda resolución de los poderes públicos (no solo las emanadas del Poder Judicial), en la que, además, su ausencia es sancionada con nulidad (apartado L) del inciso $7^{\circ}$ del art. 76).

Con su constitucionalización, la motivación de las resoluciones judiciales deja de ser únicamente una garantía para las partes del proceso y el tribunal de alzada para desplegar una función más amplia aún. Esto es, deja de tener una función exclusivamente endoprocesal para ejercer también una función extraprocesal permitiendo el contralor de la actividad judicial por parte de la sociedad. Es que, en un Estado democrático, la sociedad ejerce legítimamente la labor de controlar a los poderes estatales a fin de determinar si estos actúan con independencia, eficiencia y respetando los postulados de la Constitución (Santana, 2016, p. 24).

Ahora bien, si la sociedad debe conocer cómo funciona el Poder Judicial, se garantiza la publicidad de su actuación otorgando mayor transparencia a la actividad de los tribunales y se disminuye, por lo tanto, la posibilidad de caer en arbitrariedades (Soba y Gaiero, 2010, 850). De esta manera se cumple con el aforismo de Mirabeau:

No le temo a los jueces, ni a los más abyectos, ni a los más depravados, ni a mis mismos enemigos, si es que su justicia deben hacerla en presencia del pueblo. Todos sabemos bien que el pueblo es el juez de los jueces (Couture, 1948, p. 153).

Como se aprecia, de esta manera se elevan las garantías que debe revestir todo sistema procesal a fin de que se encuentre inserto dentro del Estado constitucional de Derecho. 
En esta concepción moderna, la motivación se vincula con el concepto de justificación del ejercicio del poder estatal. En efecto, las decisiones emanadas de uno de los poderes del Estado deben ser justificadas frente a las partes y a la sociedad en su conjunto para evitar caer en una arbitrariedad, precisamente como forma de controlar su ejercicio y para garantizar los derechos y libertades de los ciudadanos. Esta vinculación puede rastrearse hasta Calamandrei (1960), uno de los padres de la Constitución italiana de 1947, quien sostuviera:

La motivación es, antes que nada, la justificación, que quiere ser persuasiva, de la bondad de la sentencia. Desde el momento en que la justicia ha descendido del cielo a la tierra, y se ha comenzado a admitir que la respuesta del juez es palabra humana y no oráculo sobrenatural e infalible, que se adora y no se discute, el hombre ha sentido la necesidad de utilizar razones humanas para declarar la justicia de los hombres (p. 116).

Aquí se encuentra inserto también el principio de publicidad de la actividad procesal (art. 7 del CGP), todo lo cual contribuye a otorgar mayor transparencia a la actividad de los tribunales minimizando el riesgo de caer en la arbitrariedad. Como se aprecia, la expansión del concepto de motivación provoca su vinculación con el principio de publicidad, repercusión que no solo se ve en este principio sino también en materia probatoria como luego se verá.

\section{Características de la motivación}

Sin fisuras, la doctrina ha señalado que la motivación de la sentencia debe reunir una serie de puntualizaciones para erigirse como una garantía constitucional del debido proceso.

En primer lugar, la fundamentación debe ser expresa. Esto es, el tribunal debe consignar expresamente los argumentos que lo llevaron a adoptar su decisión (Landoni et al., 2004, p. 622; Vescovi et al., 2000, p. 65). Por lo tanto, no resulta admisible que se remita "a los fundamentos expuestos" en una decisión anterior, a lo postulado por la doctrina o incluso la jurisprudencia sobre el punto en cuestión.

Asimismo, debe ser clara, esto es, fácilmente comprensible. Esta característica se ha desarrollado con énfasis con la evolución de la función extraprocesal de la motivación 
ya referida. En efecto, si consideramos a la motivación de las sentencias como un mecanismo de justificación del ejercicio del poder que tenga como finalidad permitir a la ciudadanía controlar dicho ejercicio, la sentencia necesariamente debe ser redactada en un lenguaje claro y entendible para el ciudadano medio.

Es cierto que el lenguaje jurídico se encuentra plagado de términos, frases, definiciones y construcciones semánticas que puedan no ser entendidas por quienes no son especialistas en la materia, y también es cierto que mucho de ese lenguaje es esencial para explicar determinados conceptos, teorías y doctrinas y su reemplazo podía hacer incurrir en error a los operadores jurídicos (Verbic, 2014). Ahora bien, por otro lado, debe señalarse que existe un bagaje de vocabulario que no resulta esencial a la hora de motivar los fallos y que bien podría eliminarse sin que las sentencias perdieran su significado ejemplo de ello son el excesivo uso de "latinazgos" para comunicar conceptos o ideas, citas textuales de autores extranjeros sin la debida traducción, etcétera- (Anderson, 2012, p. 1-40). Asimismo, debe recordarse que las sentencias son la forma específica de comunicación institucional del Poder Judicial en general y de los jueces en particular, por lo que estos necesitan ser bien comprendidos por diferentes auditorios (litigantes, foro, academia, opinión pública) y por ello, deben expresarse correctamente, usando un lenguaje claro, preciso, comprensible y medido, aunque sin desmedro de su calidad técnica (Castro, 2016).

Calamandrei (1960, p. 116-117) ha enseñado que la motivación constituye la parte razonada de la sentencia, que sirve para demostrar que el fallo es justo y por qué es justo, por lo que necesariamente la misma deberá ser lógica. Ello implica que, si bien el tribunal tiene libertad para apreciar y valorar la prueba, disponiendo de amplitud para decidir qué eficacia le asigna a la que se ha producido, no puede incurrir en arbitrariedad al sentenciar ya que su razonamiento está constreñido por las reglas de la sana crítica que le imponen límites marcados por el recto entendimiento humano (Vescovi et al., 2000, p. 68). A este límite puede agregársele otro cuando existan pruebas cuyo valor probatorio se encuentre determinado (de acuerdo con el régimen de la prueba tasada).

Asimismo, se ha incluido a la coherencia de la motivación a fin de no violar principios básicos del pensamiento lógico. La Suprema Corte de Justicia reiteradamente ha señalado que la "la decisión debe ser internamente coherente, so pena de incurrir no ya en incongruencia, sino en falta de motivación" (s. No. 349/2009, 02/10/2009, Gutiérrez (r), Larrieux, Van Rompaey, Posada, Ruibal Pino; 3.636/2011, 28/09/2011, 
Chediak (r), Van Rompaey, Gutiérrez, Ruibal Pino, Larrieux; 349/2012, 08/02/2012, Ruibal Pino (r), Gutiérrez, Van Rompaey, Chediak, Larrieux; 18/2013, 18/02/2013, Chediak (r), Chalar, Larrieux, Pérez Manrique, Ruibal Pino; 321/2016, 08/09/2016, Larrieux (r), Martínez, Chediak, Hounie, Larrieux, Pérez Manrique, entre otras).

Sobre este punto se habla de una justificación (aunque en un sentido diverso respecto al empleado anteriormente) interna del fallo que requiere que la decisión se deba poder inferir lógicamente de las premisas fácticas y normativas seleccionadas y expresadas como fundamento de hecho y de derecho (Castro, 2016, p. 912). A ella debe agregarse, para casos de difícil resolución, una justificación externa que no apunta a una corrección desde el punto de vista lógico sino a las premisas (fácticas y normativas) que se emplean en ese razonamiento. El razonamiento puede ser impecable, pero si las premisas no con correctas, ese defecto se trasmite a la conclusión. Que una premisa sea correcta significa que es aceptada sin provocar desacuerdos, o bien a pesar del desacuerdo se ha justificado en su incorporación (Castro, 2016).

Dentro del carácter lógico se encuentra la motivación de acuerdo "a las máximas de la experiencia" o al "sentido común", conceptos muchas veces utilizados para justificar las decisiones jurisdiccionales. El problema se encuentra en que constituyen conceptos difusos, indeterminados e imprecisos, no existiendo siempre unanimidad sobre su alcance y contenido, por lo que se debe ser cauto en su utilización (Soba, 2016, p. 166-167). Se trata de nociones dinámicas que pueden variar según el tiempo y espacio, debiendo examinarse si revisten actualidad o si el paso del tiempo ha hecho que las bases sobre las cuales se habían edificado, se hayan visto modificadas (Klett, 2014, p. 189). Por lo tanto, cuando se acude a las nociones de máxima de la experiencia o sentido común, el deber de motivación resulta incrementado (Soba, 2016, p. 168), teniendo en cuenta además que para algunos autores las reglas de la experiencia no necesitan prueba por su carácter de notorias, por integrar el saber de cualquier hombre de mediana cultura (Vescovi et al., 1998, p. 229).

Finalmente, la motivación debe ser completa abarcando tanto a los hechos como al derecho. Esta característica, por sus particularidades, será tratada a continuación al analizar el contenido del art. 197 CGP. 


\section{Artículo 197 del Código General del Proceso}

El CGP recoge en su art. 197 una concepción que tradicionalmente ha sido seguida en doctrina entendiendo a la motivación como un concepto comprensivo tanto de la fundamentación fáctica como de la fundamentación jurídica de las sentencias (Vescovi et al., 2000, p. 62; Tarigo, 2004, p. 199). En efecto, en lo que respecta a la primera (fundamentación fáctica) el artículo establece que el tribunal debe indicar "los hechos que se tienen por ciertos" esto es, aquellos cuya existencia o inexistencia se resuelve independientemente de la actividad probatoria, (por ej. los hechos cuya existencia se presume por la ley en forma absoluta, aquellos que pudiendo ser controvertidos no lo fueron quedando comprendidos por la regla de la admisión) y "los que han sido probados" aludiendo a aquellos cuya afirmación de existencia o inexistencia por parte del tribunal depende de la prueba (Abal Oliú, 2016, p. 107). Es que, como señala Taruffo, el fenómeno de la prueba de los hechos y el de la motivación de la sentencia mantienen una relación muy estrecha, casi de recíproca implicación (2013, p. 91).

Como expresa Abal Oliú (2016):

El juez debe explicar porque se tienen por existentes o inexistentes determinados hechos al margen de la prueba, y, cuando la existencia o inexistencia resulta de la prueba, el juez debe explicar en las resultancias de que medios de prueba es que se funda para establecer tal existencia o inexistencia, explicando al efecto la valoración que realiza de las resultancias de cada uno de los medios de prueba producidos y explicando porque se considera, a cada uno de ellos, eficaz o ineficaz para dar por existente o inexistente el hecho (p. 107).

La motivación en materia probatoria cumple un rol determinante para las garantías de los justiciables dado que, si la valoración de la prueba no es tenida en cuenta a la hora de motivar la sentencia, no es posible ejercer esenciales elementos del debido proceso como lo es el derecho a impugnar las decisiones. Al hablar de valoración de la prueba en la motivación deben observarse no solo los medios que el tribunal valoró positivamente para fundamentar su decisión, sino también aquellos contrarios a tal conclusión. Por ello no se comparte la opinión de Klett (2014, p. 211-212) al respecto, quien analizando el art. 140 CGP considera que no existe mandato que obligue al tribunal a pronunciarse expresamente en la sentencia sobre todos los medios examinados, por lo que solo debe 
enumerar, reseñar y analizar aquellos en los que funda su resolución. Admitir la situación inversa, esto es, que se motive la sentencia solo con base en las pruebas favorables al juicio que realizó el tribunal sobre los hechos, implica el riesgo del confirmation bias o sesgo de confirmación que tiene lugar toda vez que se selecciona la información disponible a fin de confirmar una evaluación propia causando una distorsión del razonamiento (Taruffo, 2013, p. 105).

El Código General del Proceso no resulta ajeno a esta regla e incluso contiene una aplicación expresa ubicada en sede de prueba pericial. En efecto, el art. 184 establece que el tribunal deberá consignar en el fallo los motivos que tenga para apartarse del dictamen pericial cuando así lo haga. Como ha señalado la doctrina, el rechazo por el tribunal del dictamen de los peritos debe basarse en razones serias que deben explicar, en un análisis crítico tanto de sus fundamentos como de sus conclusiones y de las demás pruebas sobre los mismos hechos, que lo lleve al convencimiento de que, o bien aquellos no aparecen suficientes o carecen de lógica o son contradictorios entre sí, o bien no existe la relación lógica indispensable entre esos fundamentos y tales conclusiones o éstas contrarían las normas generales de la experiencia o hechos notorios y otras pruebas más convincentes o resultan absurdas o increíbles o dudosas por otros motivos (Devis Echandía, 1972, p. $348)$.

Se reitera que no se trata de una regla únicamente vinculada a la prueba pericial, sino el art. 184 no hace más que consignar para tal medio de prueba una regla general aplicable a todos los medios de prueba. Por ello, Abal Oliú (2018, p. 319) ha señalado que, en lo que respecta a este punto, el artículo no debe implicar nada especial, pues tal es la regla de motivación que siempre deberá seguir el tribunal cuando se basa para su fallo en las resultancias de un medio de prueba o cuando descarta las mismas.

Lamentablemente, la motivación en materia probatoria continúa siendo un punto débil de las sentencias, ya que muchas veces es dejada de lado por los tribunales quienes al valorar la prueba que se limitan a señalar que un hecho se tiene por existente o inexistente en mérito a las resultancias de los medios probatorios producidos.

Por su parte, a la denominada fundamentación del Derecho se refiere el artículo cuando indica que "le seguirá la exposición de las razones jurídicas en cuyo mérito se aplica el derecho" (Vescovi et al., 2000, p. 62). Ello significa que se debe explicar cuál es el Derecho aplicable a los hechos que se consideran existentes o inexistentes, procedimiento denominado "subsunción", entendida como el enlace lógico de una 
situación particular y concreta, con la prevista abstracta, genérica e hipotética contenida en la Ley (Santana, 2016, p. 23).

Respecto a ella, el tribunal deberá analizar todos los fundamentos de Derecho que han sido esgrimidos por las partes, argumentando sobre su aceptación o rechazo. Aquí entra en juego el principio iura novit curia, el cual permite que el fundamento jurídico del fallo se aparte de las normas jurídicas alegadas por los interesados. Como es sabido, son todas las normas de Derecho las que forman parte del objeto del proceso, con presidencia de que hayan sido o no alegadas por las partes.

No obstante, y aunque resulta indiscutible la vigencia de esta regla, como ha señalado la Suprema Corte de Justicia:

El Tribunal puede seleccionar las normas que se adapten al caso aunque no hayan sido invocadas por las partes, pero siempre lo debe hacer respetando los hechos y la requisitoria que conforman el objeto del proceso, de modo que no puede modificarse la "causa petendi" (s. No. 186/2016, 13/06/2016, Martínez (r), Larrieux, Chediak, Pérez Manrique, Hounie).

Es que el tribunal no puede hacer lugar a lo peticionado encuadrando los hechos en una categoría diferente de aquella sobre la que el actor pidió el pronunciamiento (Abal Oliú, 2015, p. 182). Por ello se concuerda con Valentin al señalar que, si no se delinea adecuadamente un marco de condiciones para el ejercicio de esta regla, su utilización puede generar violaciones a los principios básicos del Derecho Procesal y desnaturalizar la idea de proceso que la Constitución garantiza (Valentin, 2013, p. 189).

\section{Ausencia de motivación}

Tanto doctrina como jurisprudencia coinciden en señalar que una motivación inexistente provoca la nulidad de la sentencia. Distinta ha sido la situación en los casos de motivación insuficiente o incompleta, entendida como aquella en la que no se indica con precisión en cuales resultancias de medios de prueba se funda la decisión respecto a la existencia de un hecho y cuáles son las reglas de Derecho que le permite tomarlos en cuenta (Abal Oliú, 2016, p. 110).

Así, la Suprema Corte de Justicia en una jurisprudencia reiterada ha entendido que no corresponde anular la sentencia "toda vez que la omisión no haya sido obstáculo para 
la emisión de un fallo justo, ni se haya coartado el derecho de defensa...porque lo que debe predominar es el finalismo jurídico sobre el formalismo legal" (s. No. 47/1989, 17/05/1989, Tommasino (r), Nicoliello, García Otero, Balbela, Addiego; 155/1991, 29/11/1991, García Otero (r), Tommasino, Addiego, Marabotto, Torello; 828/1995, 30/10/1995, Cairoli (r), Alonso De Marco, Marabotto, Torello, Mariño; 223/1997, 28/07/1997, Torello (r), Cairoli, Marabotto, Alonso De Marco, Mariño; 343/1999, 08/12/1999, Mariño (r), Alonso De Marco, Marabotto, Cairoli, Guillot; 155/2001, 03/08/2001, Guillot (r), Cairoli, Alonso De Marco, Mariño, Parga; 2.432/2010, 24/12/2010, Ruibal Pino (r), Gutiérrez, Van Rompaey, Chediak, Larrieux; 663/2012, 29/06/2012, Pérez Manrique (r), Gutiérrez, Chediak, Larrieux, Ruibal Pino; 691/2014, 16/07/2014, Chediak (r), Chalar, Larrieux, Pérez Manrique, Ruibal Pino, entre otras). Ahora bien, esta remisión al principio de finalismo resulta cuanto menos peligrosa por elementales razones, mal puede apreciarse si la sentencia cumplió con la finalidad de ser justa si no explicita adecuadamente el razonamiento que la motivó (Giuffra, 2017, p. 110; Soba y Gaiero, 2010, p. 858).

Por lo tanto, determinar si estamos frente a un caso de ausencia de motivación, o bien, frente a una motivación incompleta, se erige como una cuestión central a la hora de aplicar sus consecuencias. En ese sentido, se ha señalado que hay ausencia de motivación cuando la sentencia carece de expresión de fundamentos o lo que se expresa no conecta la cuestión en debate con el fallo, en cambio será incompleta cuando omite justificar alguno de los puntos que resuelve (lo que no debe confundirse con la incongruencia por omisión de resolver algo en el fallo) como por ej. los criterios para evaluar un daño que se ordena indemnizar (Castro, 2016).

\section{¿Vicio in procedendo o in iudicando?}

Una cuestión controvertida consiste en determinar si la ausencia de motivación constituye un supuesto de error in procedendo o en cambio, si se trata de un vicio in iudicando. Su determinación no se trata de una cuestión menor dado que, como es sabido, en el primer caso la Suprema Corte de Justicia anulará el fallo y remitirá los autos al tribunal subrogante, mientras que en el segundo será la propia Corporación la que dicte la sentencia.

Por un lado, se ha sostenido que la motivación constituye una exigencia estructural de la sentencia, por lo que su ausencia (provocada por un incumplimiento de un deber 
funcional del tribunal conforme al art. 197 CGP), no afecta la validez del proceso sino el contenido de la resolución. Por lo que, de acuerdo con esta postura, se trata de un error in iudicando y por ende le competerá a la Suprema Corte de Justicia pronunciarse sobre el fondo, reemplazando los fundamentos jurídicos erróneos por los que estime correctos (SCJ integrada - s. No. 309/2003, 31/10/2003, Gutiérrez (r), Parga, Van Rompaey, Troise, Piatniza). Esta posición ha sido compartida por la actual ministra Martínez en discordias de s. No. 398/2016, 05/10/2016, Chediak (r), Larrieux, Hounie, Pérez Manrique, Martínez (disc.); 358/2017, 06/04/2017, Turell (r), Chediak, Hounie, Pérez Manrique, Martínez (disc.) y 1.189/2019, 24/06/2019, Tosi (r), Chediak, Turell, Minvielle (disc.), Martínez (disc.).

Por otro lado, en forma mayoritaria, se ha considerado a la falta de motivación como un vicio en el procedimiento causado por una violación al deber impuesto por los artículos 197 y 198 del CGP. En ese sentido la Corporación ha expresado:

\section{Corresponde previamente precisar que la falta de fundamentación, en tanto constituye uno de los requisitos formales de la sentencia, es un vicio ‘in procedendo' por cuanto el Juzgador no es que yerre en su juicio, sino que no procede para establecerlo de la manera que la Ley le indica (s. No. 9/2001, 28/02/2001, Mariño (r), Cairoli, Alonso, Parga, Guillot).}

Asimismo, al tratarse de una garantía esencial del debido proceso la falta de motivación encarta como causal de casación dentro de lo previsto en el art. 270 inciso segundo del CGP (Suprema Corte de Justicia, s. No. 19/2009, 13/02/2009, Larrieux (r), Van Rompaey, Rodríguez Caorsi, Ruibal Pino, Gutiérrez (disc.); 358/2017 y 1.189/2019 ya citadas).

Vinculado a ello, la motivación contradictoria con el fallo ha sido equiparada a falta de motivación y, por ende, considerándosela también como error in procedendo. Al respecto se ha señalado que "la contradicción que presenta la sentencia en sus disposiciones o declaraciones, implica la imposibilidad de saber cuál fue el verdadero fallo del tribunal lo que impide que pueda ser atacado por error in judicando" poniéndose de manifiesto el carácter lógico de la motivación al indicar que en sociedades democráticas lo que importa no sólo son las decisiones sino las razones que pueden darse en favor de esa decisiones, operación intelectual vulnerada por un fallo contradictorio a la fundamentación (SCJ - s. No. 398/2016 ya citada). 


\section{Cambio de postura: Necesaria motivación que la fundamente}

Si consideramos a la sentencia producto de una actividad reflexiva del tribunal, en donde la motivación juega un rol determinante en la justificación del ejercicio del poder evitando que el pronunciamiento sea el resultado de su obrar discrecional, debemos concluir que la fundamentación también debe encontrarse presente en el cambio de postura del tribunal respecto a cuestiones análogas sobre las que se ha pronunciado anteriormente.

Con ello no se está señalando que el tribunal no pueda modificar su postura, pues en modo alguno su jurisprudencia anterior lo vincula en forma definitiva como sucede con el precedente judicial obligatorio (stare decisis) propio del common law, sino que al hacerlo debe explicitar las razones que lo han llevado a adoptar una decisión diversa; siguiendo a Alexy, "quien quiera apartarse de un precedente, asume la carga de la argumentación" (1989, p. 265). Por su parte, Klett agrega "el magistrado tiene el derecho - y el deber - de cambiar de posición, si la consideración de nuevos argumentos, nuevas obras o sentencias le hacen mudar de criterio o si ello acontece en el reexamen de los viejos argumentos o posiciones" (2014, p. 219). Sobre el punto, la Suprema Corte de Justicia en práctica constante ha indicado:

En nuestro régimen el apartamiento del precedente (a fortiori, la solución contraria a la aplicada previamente en caso similar por el mismo tribunal) impone la necesaria invocación de nuevos argumentos cuya fuerza persuasiva enerve la fundamentación del precedente. [...] Naturalmente, la consulta necesaria al precedente no impide que el juez en ejercicio de su independencia, inherente a la función jurisdiccional, descarte su mecánica aplicación al caso similar de verificación temporal sucesiva. Una adecuada fundamentación, motivación o esfuerzo argumental tendiente a dotar de racionalidad y justificabilidad a su decisión legitima el apartamiento del precedente. Pero lo que no resulta admisible es el desvío del antecedente jurisprudencial sin siquiera realizar el mínimo intento de desvirtuar o enervar los argumentos sobre los que se erigiera la conclusión contraria respecto de similar quastio decidendi (s. No. 101/2008, 16/05/2008, Van Rompaey (r), Gutiérrez, Larrieux, Ruibal Pino (disc.), Rodríguez Caorsi (disc.); 113/2008, 16/05/2008, Van Rompaey (r), Gutiérrez, Larrieux, Ruibal Pino, Rodríguez Caorsi (disc.) 119/2008, 26/05/2008, Van Rompaey (r), Gutiérrez, Larrieux, Ruibal Pino (disc.), Rodríguez Caorsi (disc.), entre otras). 


\section{Conclusiones}

Como se aprecia de lo expuesto, la motivación de las sentencias es una exigencia relativamente moderna que nació producto no del avance de la ciencia jurídica sino por razones políticas como un mecanismo de contralor de la actividad jurisdiccional. Sin embargo, con ello se provocó el nacimiento de una garantía para los justiciables, luego elevándose su rango a un requisito esencial del debido proceso y componente indiscutible del derecho a la tutela jurisdiccional efectiva.

Su consagración como elemento inherente al derecho procesal fundamental al debido proceso se produjo con la expansión de su contenido que ya no puede ser restringido a las partes del proceso y al tribunal que dictó el fallo y así como al de alzada superando su identificación como un mero requisito formal de las sentencias, sino que actualmente se proyecta a la sociedad en su conjunto como forma de justificar el ejercicio del poder estatal.

Debe insistirse en la íntima vinculación entre la motivación de las sentencias y la valoración de la prueba, así como el ejercicio de la sana crítica. En ese sentido, ya no puede considerarse que una sentencia se encuentra motivada cuando solo hace referencia a los medios de prueba que dieron mérito a la decisión, sino que el tribunal tiene el poderdeber de pronunciarse también sobre aquellos elementos probatorios contrarios a la decisión que arribó.

Teniendo en cuenta lo mencionado, y ya sea que se considere que la ausencia de motivación constituye un error in procedendo o un vicio in iudicando, los tribunales deben evitar realizar cualquier remisión al principio de finalismo como criterio que permita suplir la necesidad de motivar el fallo, practica debe ser rechazada ya que es la propia exigencia del debido proceso que impone explicitar el razonamiento seguido para arribar a la decisión y que permitirá verificar si la sentencia ha cumplido con la finalidad de ser justa.

\section{Referencias}

Abal Oliú, A. (2015). Derecho Procesal. Tomo III (4ª ed.). Montevideo, Uruguay: Fundación de Cultura Universitaria.

Abal Oliú, A. (2016). Derecho Procesal. Tomo V (1ª ed.). Montevideo, Uruguay: Fundación de Cultura Universitaria. 
Abal Oliú, A. (2018). Derecho Procesal. Tomo IV (3 $3^{\text {a ed. }) . ~ M o n t e v i d e o, ~ U r u g u a y: ~ F u n d a c i o ́ n ~ d e ~}$ Cultura Universitaria.

Alexy, R. (1989). Teoría de la argumentación jurídica. Madrid, España: Centro de estudios constitucionales.

Anderson, M. (2012). Acceso a la justicia y al proceso legal: creando instituciones legales más receptivas a los pobres en los países en desarrollo. La garantía de acceso a la justicia: aportes empíricos y conceptuales. Recuperado de http://www.corteidh.or.cr/tablas/28920.pdf

Barbieri, L. (2010). La motivación de las sentencias judiciales. Revista Uruguaya de Derecho Procesal, 3(4), 787-796.

Barrios De Ángelis, D. (2005). Teoría del Proceso (2 ${ }^{\mathrm{a}}$ ed.). Buenos Aires, Argentina: B de F.

Calamandrei, P. (1945). La casación civil. Tomo I. Vol. I. Buenos Aires, Argentina: Bibliográfica Argentina.

Calamandrei, P. (1960). Proceso y Democracia. Buenos Aires, Argentina: Ediciones Jurídicas Europa-América.

Castro, A. (2016). Principio de tutela judicial efectiva y motivación de la sentencia. Estudios de Derecho Administrativo, 14, 895-935.

Colomer Hernández, I. (2003). La motivación de las sentencias: sus exigencias constitucionales y legales. Valencia, España: Tirant lo Blanch.

Couture, E. J. (1948). Estudios de Derecho Procesal Civil. Tomo I. Buenos Aires, Argentina: Ediar.

Couture, E. J. (2007). Fundamentos de Derecho Procesal Civil (4a ed.). Buenos Aires, Argentina: B de F.

Devis Echandía, H. (1972). Teoría General de la Prueba Judicial. Tomo II. Buenos Aires, Argentina: Victor P. De Zavalia.

Gil Cremades, J. J. (1983). La motivación de las decisiones jurídicas. En F. E. Rodríguez García (Coord.), Estudios en honor del doctor Luis Recaséns Siches, t. I (pp. 415-433). Recuperado de http://ru.juridicas.unam.mx:80/xmlui/handle/123456789/10018

Giuffra, C. (2017). Los recursos judiciales en el Código General del Proceso. Tomo II (1 $\left.1^{\mathrm{a}} \mathrm{ed}.\right)$. Montevideo, Uruguay: Fundación de Cultura Universitaria.

Gozaíni, O. A. (2014). Tratado de Derecho Procesal Constitucional Latinoamericano. Tomo I. Buenos Aires, Argentina: La Ley.

Guerra, W. y Guerra, M. (2018). Apelación y Segunda instancia. Un derecho con fuente en la Constitución y en el Derecho internacional de Derechos Humanos. En J. Veiras (Coord.), Procesos Constitucionales. Revista Uruguaya de Derecho Procesal (pp. 10911109). Montevideo, Uruguay: Fundación de Cultura Universitaria.

Klett, S. (2014). Proceso ordinario en el Código General del Proceso. Tomo II ( $\left.1^{\mathrm{a}} \mathrm{ed}.\right)$. Montevideo, Uruguay: Fundación de Cultura Universitaria. 
Landoni, Á., Gomes, F., Valentin, G., Prato, M., Garderes, S., y González, M. E. (2004). Código General del Proceso. Vol. II. Buenos Aires, Argentina: B de F.

Risso Ferrand, M. (2011). Algunas garantías básicas de los Derechos Humanos (2ª ed). Montevideo, Uruguay: Fundación de Cultura Universitaria.

Santana, R. (2016). La motivación de la sentencia como contenido del derecho a la tutela judicial efectiva. Judicatura, 61, 15-27.

Soba, I. (2016). Las reglas de la experiencia y el sentido común en la decisión jurisdiccional, $L a$ Justicia Uruguaya, 154, 165-175.

Soba, I., y Gaiero, B. (2010). La sana crítica y la motivación de las decisiones jurisdiccionales en materia probatoria. Revista Uruguaya de Derecho Procesal, 3(4), 845-859.

Tarigo, E. (1987). Sentencia. En Curso de Derecho Procesal. Instituto Uruguayo de Derecho Procesal. Tomo II ( $2^{\text {a }}$ ed.) (pp. 291-325). Montevideo, Uruguay: Fundación de Cultura Universitaria.

Tarigo, E. (2004). Lecciones de Derecho Procesal Civil. Tomo II ( $3^{\mathrm{a}}$ ed.). Montevideo, Uruguay: Fundación de Cultura Universitaria.

Taruffo, M. (2006). La motivación de la sentencia civil. México D.F., México: Tribunal Electoral del Poder Judicial de la Federación.

Taruffo, M. (2013). Verdad, prueba y motivación en la decisión sobre los hechos. México D.F., México: Tribunal Electoral del Poder Judicial de la Federación.

Valentin, G. (2013). Principio de congruencia y regla iura novit curia en el proceso civil uruguayo ( $1^{\mathrm{a}}$ ed.). Montevideo, Uruguay: Fundación de Cultura Universitaria.

Verbic, F. (2014). La motivación de la sentencia como elemento esencial del debido proceso legal en los países integrantes del sistema interamericano de protección de derechos humanos. Recuperado de https://www.academia.edu/6215505/Motivaci\%C3\%B3n_de_la_sentencia_y_debido_pr oceso_en_el_sistema_interamericano

Vescovi, E., De Hegedus, M., Klett, S., Cardinal, F., Simón, L. M., Pereira Campos, S. (1998) Código General del Proceso. Tomo 4. Buenos Aires, Argentina: Ábaco.

Vescovi, E., De Hegedus, M., Klett, S., Cardinal, F., Simón, L. M., Pereira Campos, S. (2000) Código General del Proceso. Tomo 6. Buenos Aires, Argentina: Ábaco.

\section{Contribución autoral}

a) Concepción y diseño del trabajo; b) Adquisición de datos; c) Análisis e interpretación de datos;

d) Redacción del manuscrito; e) revisión crítica del manuscrito.

G. F. V. P. ha contribuido en a, b, c, d, e.

\section{Editor científico responsable}

Dra. María Paula Garat 